\title{
Assessment of intellectual capital management in Taiwanese IC design companies: using DEA and the Malmquist productivity index
}

\section{Wann-Yih Wu ${ }^{1}$, Hsin-Ju Tsai ${ }^{2}$, Kuei-Yang Cheng ${ }^{1}$ and Mengkuan Lai ${ }^{1}$}

\author{
${ }^{1}$ National Cheng Kung University, No.1, University Road, Taiwan, 70101, Taiwan. \\ wanyi@mail.ncku.edu.tw; mklai@mail.ncku.edu.tw \\ ${ }^{2}$ The University of Manchester, MBS East, PO Box 88, Manchester, M60 1QD, UK. hsin-ju. \\ tsai@postgrad.manchester.ac.uk
}

\begin{abstract}
While withstanding a highly competitive environment, an increasing number of firms have recognized that intangible assets rather than tangible ones are vital to achieving competitive advantages. Intellectual capital has replaced physical capital as the primary basis of value creation. Although the importance of intellectual capital in ensuring superior competitive advantages is well accepted, exactly how these two constructs are related has seldom been investigated, particularly for the high-technology industry. Taking a sample of 39 Taiwanese IC design companies, this study adopted data envelopment analysis and the Malmquist productivity index to evaluate the impact of intellectual capital on competitive advantage. The analytical results revealed that approximately one third of the companies sampled had excellent efficiency in intellectual capital management, while the others still had considerable room to improve their intellectual capital management. The results of this study provide a valuable reference for future studies in alternative contexts.
\end{abstract}

\section{Research background}

\footnotetext{
A s the growing demand for knowledge-based products and services is shaping the global economic landscape, the role of knowledge in achieving competitive advantage has become a major consideration in management. As is increasingly recognized, intellectual capital has replaced physical capital as the key factor underlying value creation in the new knowledge economy (Bontis, 1999, 2001; Pulic, 2000).
}

Intellectual capital determines firm-competitive advantage.

Many studies have conferred upon the importance and content of intellectual capital (Edvinsson and Malone, 1997; Stewart, 1997; Sullivan, 2000; Bontis, 2001). Van Buren (1999) further discusses how to transform intellectual capital into competitive advantage but from a more conceptual aspect. Research on intellectual capital management from an empirical perspective still seems to be insufficient. How to leverage 
intellectual capital effectively has seldom been investigated empirically and is still subject to further study. To achieve the above research objectives, this study selected the integrated circuit (IC) design industry as an empirical research target. Unlike other IC companies, IC design companies rely little on physical capital investment. Rather, the intellectual capital possessed by IC design firms is what determines their survival.

IC design is the 'fabless' sector of the semiconductor industry. IC design firms do not need/own fabs (fabrication plants). The value of an IC design company lies in the brains of its engineers and support staff. Intellectual property and research and development $(\mathrm{R} \& \mathrm{D})$ teams are at the core of IC design companies, which has made intellectual capital especially crucial to IC design companies (Brown et al., 2005). Thus, the IC design industry serves as an ideal target for research on intellectual capital. With limited resources, the Taiwanese IC design industry has established a core competence in terms of speed, quality, flexibility and cost via knowledge assimilation and utilization (Chang and Tsai, 2002; Breznitz, 2005; Wang and Tsai, 2005). Numerous previous studies indicate that the success of Taiwanese IC firms was owing to their effective management of intellectual capital particularly in maintaining intellectual property and $R \& D$ teams.

Data envelopment analysis (DEA) is a typical performance assessment approach to evaluate the efficiency of a group of companies. DEA is particularly useful for practitioners to adopt benchmarking, as firms can easily identify the efforts required to catch up with benchmarking partners by examining their performances. Malmquist productivity index (MPI) is a method to evaluate the changes of efficiency among firms in a certain period of time. It is a useful benchmarking tool to examine the relative firm progress among competitors. In the past two decades, more than 3,000 publications have adopted DEA and/or MPI as the evaluation techniques to assess firm efficiency. However, to date, there is no application on intellectual capital management performance. It is expected that adoption of DEA/MPI to benchmarking of intellectual capital can provide valuable information for IC design companies to compete in the marketplace. According to Chang and Tsai (2002), the Taiwanese IC industry did not aggressively seize technology leadership but rather focused on being a quick follower. Such an industry structure is more appropriate for a researcher to evaluate operation efficiency using DEA. Therefore, Taiwanese IC firms make an ideal sample for the purposes of this study.

This study has the following objectives: (1) to establish an assessment model to measure the intellectual capital of Taiwanese IC design companies and use this model to identify the companies that are on the efficient frontier; (2) to evaluate the performance of 39 Taiwanese IC design companies; (3) to verify the amount of slack for inefficient companies to improve; and (4) to examine changes in the efficiency of 39 IC design companies from 1999 to 2002. The findings have clarified the efficiency measurement of firms in converting intellectual capital into competitive advantage. The findings could also be helpful for business managers to make decisions on intellectual capital investments and to assess the value and effectiveness of intellectual capital management.

\section{Literature review}

\subsection{Intellectual capital}

Since the early 1980s, intellectual capital has received considerable attention in management research. However, only during the recent decade has intellectual capital, also referred to as intangible assets, come to be perceived as a major determinant of company profits and competitive advantages. Although there is so far no consensus on the definition of intellectual capital, Edvinsson and Malone (1997) give a more comprehensive view of intellectual capital as 'knowledge that can be converted into value.' Sullivan (2000) further divides intellectual capital into three categories: human capital, structural capital and customer capital. Other studies have focused on various manifestations of intellectual capital, including corporate culture, brands and expertise. Nevertheless, it is still widely accepted that intellectual capital is something knowledge-based, captured in an identifiable form and useful in organizations. Thus, intellectual capital can be viewed as the accumulation of knowledge-based capital or knowledge-based equity that a firm possesses. Firms need to classify and quantify these intangible assets and evaluate their competitiveness.

As indicated by the research objectives of this study, the measurement of intellectual capital is crucial. What is not measured is not managed. Measurement is a prerequisite for effective management. A feasible measurement system thus is a crucial first step in achieving intellectual capital 
management. Without a proper instrument to measure intellectual capital, managers may misjudge the revenue potential and value-added benefits of intellectual capital (Johnson, 1999). Sveiby (1997) suggests four main measuring approaches: (1) direct intellectual capital methods, (2) market capitalization methods, (3) return on assets (ROA) methods and (4) scorecard methods. However, to date, no single best solution has been identified. Considering the purposes of this research and the selected target firms, this work applied the ROA method to measure the intellectual capital stocks of Taiwanese IC design companies. Adopting ROA to measure monetary values and intellectual stocks enables companyto-company comparisons using audited financial data to provide signals to top management.

\subsection{Relationship between intellectual capital and competitive advantage}

Intellectual capital as a source of competitive advantage has attracted attention among both academics and managers (Edvinsson and Malone, 1997; Roos and Roos, 1997; Stewart, 1997; Sveiby, 1997; Kfir, 2000). To measure, manage and develop intellectual capital has become crucial in the current marketplace. Based on the resource-based view, firms gain competitive advantage and superior performance through acquiring, holding and subsequently using strategic assets (namely, both tangible and intangible assets) that are vital to developing competitive advantage and achieving strong financial performance (Wernerfelt, 1984). Although organizations are well aware of the value of strategic tangible assets, many are only vaguely aware of their investments in intangible assets and the associated returns. Owing to the shortage of intellectual capital measurement method, organizations tend to neglect its full potential and thus underinvest or overinvest. Consequently, the greater the efforts companies devote to managing knowledge and developing intellectual capital, the greater the competitive advantages they may gain. Intellectual capital, as a strategic intangible assets, then affects organizational performance and competitive advantage (Barney, 1991; Amit and Schoemaker, 1993).

Van Buren (1999) proposes an intellectual capital management model to explain the transformation process from intellectual capital stocks to firm performance. This model suggests that knowledge management processes and enablers are the key leverage points for enhancing firm ability to manage knowledge. Via better management of intellectual capital, firms can improve the coordination of the entire input-output transformation. The model further illustrates the impact of intellectual capital on firm performance and competitive advantage.

\subsection{DEA and MPI}

In the manufacturing industry, a firm utilizes various resources (inputs) and produces tangible goods or intangible services (outputs) to satisfy the needs of customers. Input refers to production factors, including capital, labor, materials and time. The production process involves the transformation of inputs into outputs. Accordingly, efficiency is often measured as the ratio of total weighted output to total weighted input.

DEA is a linear programming-based technique proposed by Charnes et al. (1978), which can be used to determine the efficiency of a group of decision-making units (DMUs) relative to an envelope (efficient frontier) by optimally weighting inputs and outputs. Additionally, DEA provides a single indicator of efficiency irrespective of the number of inputs and outputs. DEA has been applied in a number of fields, including education institution, healthcare, banking and high-tech manufacturing. A number of studies have used DEA as an evaluation technique, some of them have evaluated the efficiency of high-technology firms from various perspectives, including manpower (Reitsperger et al., 1993; Thore et al., 1996; Cooper et al., 2001; Despotis, 2005), cost (Kozmetsky and Yue, 1998; Kauffmann and Unal, 2000), technology (Linton and Cook, 1998; SubbaNarasimha et al., 2003), R\&D (Oral et al., 1991; Linton et al., 2002; Verma and Sinha, 2002) and profits (Shao and Lin, 2002; Verma and Sinha, 2002). While DEA is now widely recognized as an evaluation approach for performance analysis of various DMUs, to date there is no direct application on intellectual capital management performance.

MPI is a method of measuring the influence of time shift in DEA. MPI is designed to calculate the geometric mean of an efficient frontier shift in a period of time (Caves et al., 1982; Sueyoshi and Goto, 2001; Hattori et al., 2005). By calculating efficiency changes in a certain period of time, firms can evaluate and compare their relative competitive positions with competitors. Meanwhile, MPI can serve as a benchmarking tool to examine firm progress. 


\subsection{IC design industry in Taiwan}

As noted above, the IC design industry is a fabless sector within the semiconductor industry. Specifically, fabless companies focus on product design, development and marketing, and cooperate with silicon wafer manufacturers, or foundries, for production. The competitiveness of fabless design companies heavily relies on intellectual property, research team and patents and trade secrets. Moreover, innovation is also crucial to such companies. The management of intellectual capital and knowledge that strengthen employee R\&D capabilities is critical to fabless companies. Thus, IC design companies are a suitable subject when discussing the relationship between intellectual capital and competitive advantages.

With total production value exceeding 4.7 billion USD, the revenue of the Taiwanese IC design industry accounted for $27.8 \%$ of global fabless semiconductor industry revenues in 2002 (second only to the United States). The unique structure of the Taiwanese IC industry fosters close cooperation among diverse elements in the value chain, from IC design, through to manufacturing and packaging and testing, making Taiwan a key player in the global semiconductor industry.

\section{Research methodology}

\subsection{Research model}

Intellectual capital is necessary to firms in both achieving and sustaining competitive advantage. Although some firms possess considerable intellectual capital, not many actually fully exploit its value. There is a significant efficiency discrepancy (slack) in which firms utilize their intellectual capital. In this study, the authors explore the following issues:

Issue 1. Which among 39 Taiwanese IC design companies most efficiently utilizes its intellectual capital?

Issue 2. Identifying a benchmarking target for inefficient companies.

Issue 3. Identifying the degree of inefficiency of inefficient companies compared with benchmarking companies.

Issue 4. Identifying recent efficiency changes of benchmarking companies, the degree to which their efficiency has been improved and which companies achieve efficiency improvement and thus can be used as a benchmark.
While most previous studies have focused on research model development and hypotheses testing, this study offers a practical methodology based on the DEA approach to examining the above problems. DEA is a feasible method to evaluate the superiority of certain firms in terms of intellectual capital and management performance. The results of DEA are then used as a basis for examining intellectual capital stocks and how much firms should improve various aspects of capital stock to achieve an efficient frontier in relation to their competitors. While some studies have applied multivariate statistics to assess differences in intellectual capital stock among firms for theoretical validation, we believe that using DEA as a complementary research approach can provide an alternative methodology that emphasizes managerial practices.

DEA calculates the relative efficiency of each company using the actual observed values of the inputs and outputs of each company. Utilizing the DEA method and the MPI (Fare et al., 1992), this study examined the relative efficiency of these IC companies as of 2002, and evaluated the shift of efficiency from 1999 to 2002.

For any specific firm $k$, the Charnes, Cooper and Rhodes (CCR) model (1978) with constant returns to scale (CRS) can be calculated using the following formula to determine its efficiency score ( $X_{i}$ represents the input variables and $Y_{r}$ represents the output variables)

$$
\begin{aligned}
& \operatorname{Min} \frac{1}{g_{k}}=\frac{\sum_{i=1}^{m} v_{i} X_{i k}}{\sum_{r=1}^{s} u_{r} Y_{r k}} \\
& \text { Subject to } \frac{\sum_{i=1}^{m} v_{i} X_{i j}}{\sum_{r=1}^{s} u_{r} Y_{r j}} \geq 1, \quad j=1, \ldots, n \\
& u_{r}, V_{i} \geq \varepsilon>0, r=1, \ldots, s, i=1, \ldots, m
\end{aligned}
$$

In the CCR model, it is assumed that an increase in the amount of input consumed will proportionately increase the amount of output produced. Banker, Charnes and Cooper (BCC) (1984) later modified the CCR model and assumed that the amount of output produced is considered to increase more or less than the proportional increase in the inputs. For a specific firm $k$, the $\mathrm{BCC}$ model with variable return to scale (VRS) can be derived using the following formula to obtain scale efficiency:

$$
\begin{aligned}
& \operatorname{Min} \frac{1}{g_{k}}=\frac{\sum_{i=1}^{m} v_{i} X_{i k}+v_{0}}{\sum_{r=1}^{s} u_{r} Y_{r k}} \\
& \text { Subject to } \frac{\sum_{i=1}^{m} v_{i} X_{i j}+v_{0}}{\sum_{r=1}^{s} u_{r} Y_{r j}} \geq 1, j=1, \ldots, n \\
& u_{r}, v_{i} \geq \varepsilon>0, r=1, \ldots, s, i=1, \ldots, m
\end{aligned}
$$


The use of the CCR model specification when not all DMUs are operating at their optimum results in measures of technical efficiency, which are confounded by scale efficiencies (SE). The use of the BCC model specification permits the calculation of technical efficiency (TE) without these scale efficiencies' effects. The scale inefficiency can be calculated based on differences between the $\mathrm{BCC}$ and the CCR technical efficiency scores. The term technical and scale efficiency (TSE) describes the technical efficiency scores obtained using a CCR model. Meanwhile, pure technical efficiency (PTE) refers to the technical efficiency scores obtained from a BCC model.

To develop a method for measuring the efficiency change from the time period $t$ to $t+1$, the efficiency distance functions $D^{t+1}\left(X_{i k}^{t}, Y_{r k}^{t}\right)$ are defined (which use the efficient frontier period $t+1$ as the reference set for measuring the efficiency of a certain DMU at period $t$ ) using the following formula:

$$
\begin{aligned}
& D^{t+1}\left(X_{i k}^{t}, Y_{r k}^{t}\right)=\operatorname{Max} \theta \\
& \text { Subject to } \sum_{j=1}^{n} \lambda_{j}^{t+1} x_{i j}^{t+1} \leq x_{i j}^{t} \\
& \sum_{j=1}^{n} \lambda_{j}^{t+1} y_{r j}^{t+1} \geq \theta y_{r j}^{t} \\
& \lambda_{j}^{t+1} \geq 0, i=1, \ldots, m, r=1, \ldots, s, j=1 \ldots, n, \\
& x_{j}^{t+1} \geq 0, i=1, \ldots, m, r=1, \ldots, s, j=1 \ldots, m \\
& \theta \text { unconstrained }
\end{aligned}
$$

MPI was calculated according to formula (4) (Caves et al., 1982):

$$
\begin{aligned}
\operatorname{MPI} & =\operatorname{MPI}\left(x_{i k}^{t}, y_{r k}^{t}, x_{i k}^{r j}, y_{r k}^{r j}\right) \\
& =\left[\left(\frac{D^{t}\left(x_{i k}^{t+1}, y_{r k}^{t+1}\right)}{D^{t}\left(x_{i k}^{t}, y_{r k}^{t}\right)}\right)\left(\frac{D^{t+1}\left(x_{i k}^{t+1}, y_{r k}^{t+1}\right)}{D^{t+1}\left(x_{i k}^{t}, y_{r k}^{t}\right)}\right)\right]^{1 / 2} .
\end{aligned}
$$

During the data analysis phase, a computer program DEAP (version 2.0) developed by Tim Coelli was adopted. DEAP is a common software that enables researchers to calculate firm relative efficiencies under both constant and various return scales. DEAP has also been applied to estimate the Malmquist Production Index for measuring the influence of time shift.

\subsection{Research variables and data collection procedure}

Following previous studies, the indicators selected as input measures include: capital (Shao and Lin, 2002), assets (Kao et al., 2003), number of employees (Cooper et al., 2001; Kao et al., 2003), number of R\&D employees (Shao and Lin, 2002), labor costs (Shao and Lin, 2002)), operating expenses (Kauffmann and Unal, 2000; Cooper et al., 2001), R\&D expenditures (Verma and Sinha, 2002) and number of patents owned (SubbaNarasimha et al., 2003). SubbaNarasimha et al. (2003) suggest that patents have face validity as measures of technological knowledge. The US Patent Classification System is function-based rather than application-based (Snow, 1983). Because of this function-based classification, patents provide an index of a firm's variety-generating capability. Patents thus represent an alternative to R\&D expenditures or number $R \& D$ employees for measuring firm innovation capacity.

This study is concerned with the metrics that can accurately reflect the relationship between intellectual capital and management performance in utilizing intellectual capital, human capital, R\&D costs and patents. This study adopted the following indicators as input variables: number of employees (X1), R\&D expenditures (X2, in thousands of NT dollars), number of patents (X3), beginning intellectual capital stocks (X4), number of R\&D employees (X5) and operating costs (X6). In this study, number of employees (X1) and number of R\&D employees (X5) are used to measure the human capital that a firm possesses and also to specify R\&D employees from other employees. R\&D expenditures (X2) are used to capture investment in firm core competences. Number of patents (X3) indicates the number of patents possessed by a company. The fourth variable, beginning intellectual capital stocks (X4), represents the monetary value of firm intellectual capital stocks, and was calculated using the calculated intangible value (CIV) method (Stewart, 1997). This valuation technique assumes that the value of intellectual capital stock represents firm ability to outperform an average competitor with similar tangible assets. The CIV method enables comparisons among companies.

Based on previous researches, the selected output indicators are: sales (Kao et al., 2003), income (Kao et al., 2003), value added (Shao and Lin, 2002), financial ratio (Chang et al., 2003; SubbaNarasimha et al., 2003), patents (Chang, 1993) and scientific and technological contribution 
Wann-Yih Wu, Hsin-Ju Tsai, Kuei-Yang Cheng and Mengkuan Lai

Table 1. List of input and output variables

\begin{tabular}{clrr}
\hline Indicator & Measure & Mean & Standard deviation \\
\hline Input & & & \\
X1 & Number of employees & 183.38 & 160.09 \\
X2 & R\&D expenditures (NTD 1,000) & $271,018.87$ & $358,147.47$ \\
X3 & Number of patents (existing patents stocks, & 12.02 & 18.05 \\
in number of patents) & & \\
X4 & Intellectual capital stocks (beginning) & $6,423,977.78$ & $3,461,321.28$ \\
X5 & R\&D employees & $1,616,841.82$ & $2,588,972.45$ \\
X6 & Operation Cost & & 17.88 \\
& & $2,676,838.46$ & $4,943,963.26$ \\
Output & & $8,400,818.07$ & $6,612,234.88$ \\
Y1 & Net sales (NTD 1,000) & $3,183,882.85$ & $3,318,420.71$ \\
Y2 & Intellectual capital stocks (end) & \\
Y3 & Changes in intellectual capital stocks (NTD 1,000) & \\
\hline
\end{tabular}

(Oral et al., 1991). The output variables adopted in this study are as follows: net sales (Y1), ending intellectual capital stocks (Y2) and changes in intellectual capital stocks (Y3). Net sales (Y1) measure business financial performance. Meanwhile, ending intellectual capital stock indicates the amount of intellectual capital remaining at the end of the year. Furthermore, changes in intellectual capital stocks (Y3) assess ongoing efforts to manage intellectual capital. To reflect fully the 'contribution of existing intellectual capital stocks' to output, this study adopted moving numbers of intellectual capital stocks. That is, changes in intellectual capital stocks $=$ (beginning intellectual capital stocks-ending intellectual capital stock).

The data were collected from the Listed Company Database of Taiwan Stock Exchange and Over-the-Counter Stock Exchange during the period 1999-2002 (Taiwan Economic Journal Data Bank). To eliminate the effects of inflation, all data were deflated with the wholesale price index deflator to convert monetary values into constant 2002 dollars.

In the system dynamics approach, both stocks or balance sheet amounts, and flows affecting stocks are important to firm management. Firms primarily or exclusively focus on the stocks of resources because of their relative ease of measurement and management. However, the flow of resources shows that the transformation process is more difficult to measure, and thus its importance should not be overlooked (Chatzkel, 2002).

Measuring growth and the rate of change of flows could also be important to firm management. This study measures firm performance using both stocks and flows of intellectual capital to measure firm performance. Additionally, the input value, namely beginning intellectual capital stocks, of this year equals the output value, namely ending intellectual capital stocks, of previous year. Moreover, the value of changes in intellectual capital stocks $=$ (beginning intellectual capital stocks-ending intellectual capital stock):

$$
\Delta \mathrm{ICS}=\mathrm{ICS}_{\mathrm{e}}-\mathrm{ICS}_{\mathrm{b}}
$$

As mentioned above, the sample was drawn from the Taiwanese IC design industry, which is a globally competitive and knowledge-based industry. The final sample size, after removing cases with missing values, comprises 39 Taiwan IC design companies that met the above criteria. All performance data were adjusted for inflation. Table 1 lists the mean and standard deviation for the input and output variables. The aggregated revenues of these 39 companies accounted for $85.81 \%$ of Taiwanese IC design industry revenues, and $67.57 \%$ of market share in 2002. Table 2 lists the names of 39 IC design companies.

DEA was applied to examine the relative efficiency of 39 Taiwan IC design companies in transforming their intellectual capital stocks into financial performance during a 4-year period (1999-2002). This study performed the data analysis in three stages. The first stage was 'relative efficiency analysis.' Based on the application procedure of DEA described by Golany and Roll (1989), the relative efficiency scores were calculated for 39 Taiwan IC design companies. Meanwhile, the second stage was 'slack analysis.' The output slack for inefficient companies was calculated to provide figures for their efficiency improvement. Efficient change analysis' was then performed utilizing MPI to assess the changes in relative efficiency among 39 Taiwan IC design companies over a 4-year period. 
Table 2. List of 39 Taiwan IC design companies

\begin{tabular}{llll}
\hline No. & IC design company (market share in 2002) & No. & IC design company (market share in 2002) \\
\hline F1 & Realtek Semiconductor Corp. (5.93) & F21 & Genesys Logic Inc. (0.71) \\
F2 & Sunplus Technology Co. Ltd. (5.59) & F22 & Princeton Technology Corp. (1.53) \\
F3 & Weltrend Semiconductor Inc. (0.94) & F23 & HiMark Technology Inc. (0.20) \\
F4 & Mediatek Incorporation. (19.10) & F24 & Anpec Electronics Corp. (0.61) \\
F5 & Elan Microelectonics Corp. (2.59) & F25 & SmartASIC Technology Inc. (0.60) \\
F6 & SpringSoft Inc. (0.46) & F26 & Holtek Semiconductor Inc. (2.11) \\
F7 & Elite Semiconductor Memory Technology Inc. (2.52) & F27 & Prolific Technology Inc. (0.33) \\
F8 & Integrated Technology Express Inc. (1.09) & F28 & Topro Technology Inc. (0.42) \\
F9 & Novatek Microelectronics Corp. (4.33) & F29 & C-Media Electronics Inc. (0.61) \\
F10 & Faraday Technology Corp. (2.18) & F30 & ENE Technology Inc. (0.23) \\
F11 & Ali Corp. (3.94) & F31 & System General Corp. (0.26) \\
F12 & King Billion Electronics Co. Ltd. (0.31) & F32 & Richtek Technology Corp. (0.71) \\
F13 & Davicom Semiconductor Inc. (0.25) & F33 & Analog Integrations Corp. (0.43) \\
F14 & Syntek Semiconductor Co. Ltd. (0.17) & F34 & Tenx Technology Inc. (0.49) \\
F15 & Myson Century Inc. (1.59) & F35 & Sitronix Technology Corp. (0.38) \\
F16 & TM Technology Inc. (0.42) & F36 & Alpha Microlectronics Corp. (0.35) \\
F17 & Sonix Technology Co. Ltd. (0.99) & F37 & Key Technology Corp. (0.86) \\
F18 & Integrated Circuit Solution Inc. (1.78) & F38 & Global Mixed-Mode Technology Inc. (0.23) \\
F19 & Tontek Design Technology Ltd. (0.21) & F39 & CoAsia Microelectronics Corp. (1.49) \\
F20 & Avid Electronics Corp. (0.63) & Total & 67.57 \\
\hline
\end{tabular}

\section{Research results}

This study discusses four main issues. Each will be further illustrated as below:

Issue 1. Which among 39 Taiwanese IC design companies most efficiently utilizes its intellectual capital?

Issue 2. Identifying a benchmarking target for inefficient companies.

Table 3 lists the relative efficiency for the 39 companies in 2002. Twenty companies had a pure technical efficiency score (PTE $\mathrm{PRS}_{\mathrm{V}}$ ) of 1.00, 18 companies had a PTE $E_{V R S}$ between 0.80 and 1.00 and one company had a PTE $\mathrm{VRS}_{\mathrm{V}}$ between 0.60 and 0.80 . The companies with efficiency score (PTE $\mathrm{VRS}_{\mathrm{VRS}}$ ) of 1 are located on the efficiency frontier. These efficient companies, such as Mediatek, Springsoft, Davicom, Myson Century, Sitronix and Key Tech, are the most distinguished companies because they are more frequently benchmarked. Table 3 also lists the benchmarking parameters for these inefficient companies.

Table 4 lists the results of input and output slack. The remaining 19 inefficient companies have some room to improve in terms of input/ output slack, as listed in Table 4. The results demonstrate that the inefficient companies can improve if the input values are markedly reduced by the gross input improvement and the output values are augmented by the output improvement. It is very important for inefficient compa- nies to discover which input or output factors require modification so that managers could identify the major problems of the company based on the results.

Issue 3. Identifying the degree of inefficiency of inefficient companies compared with benchmarking companies.

Among the 39 sampled Taiwan IC design companies, 20 companies were believed to manage intellectual capital more efficiently than the other 19. The results of ratio analysis of output/ input values comparing efficient and inefficient companies (as shown in Table 5) indicate that the values of sales and changes of intellectual capital stocks for efficient companies exceeded those for inefficient companies. Efficient IC design companies performed considerably better in terms of every ratio of outputs over inputs. Based on the input and output slacks as listed in Table 4, it is suggested that inefficient firms seeking to catch up with the efficient firms must reduce their employee numbers to achieve an efficient frontier. Four out of 19 inefficient firms tended to spend too much on R\&D and adopt too many patents for their operations. This situation indicates that managers need to be extremely cautious in monitoring the performance and effectiveness of R\&D activities and patent applications. Executives should be aware of the efficiency of resource allocation in seeking to obtain competitive advantages in 
Wann-Yih Wu, Hsin-Ju Tsai, Kuei-Yang Cheng and Mengkuan Lai

Table 3. Relative efficiency

\begin{tabular}{|c|c|c|c|c|c|c|c|}
\hline No. & Companies & $\mathrm{TE}_{\mathrm{CRS}}$ & PTE $_{\text {VRS }}$ & SE & RTS & $\begin{array}{l}\text { Reference groups } \\
\text { (benchmarking partners) }\end{array}$ & Frequency \\
\hline $\mathrm{F} 4$ & Mediatek & 1.000 & 1.000 & 1.000 & CRS & $\mathrm{F} 4$ & 14 \\
\hline F6 & Springsoft & 1.000 & 1.000 & 1.000 & CRS & F6 & 5 \\
\hline F7 & ESMT & 1.000 & 1.000 & 1.000 & CRS & F7 & 0 \\
\hline F11 & Ali & 1.000 & 1.000 & 1.000 & CRS & F11 & 3 \\
\hline F13 & Davicom & 1.000 & 1.000 & 1.000 & CRS & F13 & 8 \\
\hline F15 & Myson Century & 1.000 & 1.000 & 1.000 & CRS & F15 & 5 \\
\hline F17 & Sonix & 1.000 & 1.000 & 1.000 & CRS & F17 & 0 \\
\hline F18 & ICSI & 1.000 & 1.000 & 1.000 & CRS & F18 & 0 \\
\hline F19 & Tontek & 1.000 & 1.000 & 1.000 & CRS & F19 & 2 \\
\hline F20 & Avid Electronics & 1.000 & 1.000 & 1.000 & CRS & F20 & 6 \\
\hline F25 & SmartASIC & 1.000 & 1.000 & 1.000 & CRS & F25 & 0 \\
\hline F30 & ENE & 1.000 & 1.000 & 1.000 & CRS & F30 & 4 \\
\hline F35 & Sitronix & 1.000 & 1.000 & 1.000 & CRS & F35 & 6 \\
\hline F37 & Key Tech & 1.000 & 1.000 & 1.000 & CRS & F37 & 6 \\
\hline F39 & CoAsia & 1.000 & 1.000 & 1.000 & CRS & F39 & 1 \\
\hline F29 & C-Media & 0.997 & 1.000 & 0.997 & DRS & F29 & 6 \\
\hline F31 & SG & 0.997 & 1.000 & 0.997 & DRS & F31 & 0 \\
\hline F38 & GMT & 0.993 & 1.000 & 0.993 & DRS & F38 & 0 \\
\hline $\mathrm{F} 14$ & Syntek Design & 0.849 & 1.000 & 0.849 & DRS & F14 & 0 \\
\hline F16 & TM Tech & 0.805 & 1.000 & 0.805 & IRS & F16 & 0 \\
\hline F1 & Realtek & 0.955 & 0.958 & 0.997 & IRS & F11, F4, F37 & 0 \\
\hline F2 & Sunplus & 0.788 & 0.806 & 0.978 & DRS & F11, F4, F37 & 0 \\
\hline F3 & Weltrend & 0.882 & 0.891 & 0.991 & DRS & F4, F13, F29, F6 & 0 \\
\hline F8 & ITE & 0.964 & 0.878 & 0.984 & IRS & $\mathrm{F} 4, \mathrm{~F} 20, \mathrm{~F} 15$ & 0 \\
\hline F9 & Novatek & 0.755 & 0.831 & 0.908 & IRS & F4, F39, F15 & 0 \\
\hline F10 & Faraday & 0.841 & 0.841 & 1.000 & & $\mathrm{~F} 13, \mathrm{~F} 6, \mathrm{~F} 4, \mathrm{~F} 20$ & 0 \\
\hline F12 & KB & 0.947 & 0.961 & 0.985 & DRS & F29, F30, F35,F4 & 0 \\
\hline F21 & Genesys Logic & 0.927 & 0.933 & 0.993 & DRS & F35, F4, F6, F29, F13 & 0 \\
\hline F22 & PTC & 0.899 & 0.914 & 0.983 & IRS & $\mathrm{F} 15, \mathrm{~F} 4, \mathrm{~F} 35, \mathrm{~F} 37, \mathrm{~F} 13, \mathrm{~F} 20$ & 0 \\
\hline F23 & HiMark & 0.853 & 0.876 & 0.975 & DRS & F13, F30, F29, F6, F31 & 0 \\
\hline $\mathrm{F} 24$ & Anpec & 0.939 & 0.942 & 0.997 & DRS & $\mathrm{F} 13, \mathrm{~F} 4, \mathrm{~F} 20$ & 0 \\
\hline F26 & Holtek & 0.782 & 0.825 & 0.949 & IRS & $\mathrm{F} 15, \mathrm{~F} 4, \mathrm{~F} 20$ & 0 \\
\hline $\mathrm{F} 27$ & Prolific & 0.979 & 0.998 & 0.981 & DRS & F13, F6, F29 & 0 \\
\hline F28 & Topro & 0.966 & 0.981 & 0.985 & IRS & F15, F13, F20, F35 & 0 \\
\hline F32 & Richtek & 0.957 & 0.960 & 0.997 & DRS & $\mathrm{F} 4, \mathrm{~F} 35, \mathrm{~F} 19, \mathrm{~F} 37$ & 0 \\
\hline F33 & Analog & 0.974 & 0.986 & 0.988 & IRS & F37, F35 & 0 \\
\hline F34 & Tenx & 0.899 & 0.915 & 0.982 & DRS & F29, F4, F35, F30 & 0 \\
\hline F36 & Alpha & 0.871 & 0.897 & 0.971 & DRS & F19, F4, F30, F29 & 0 \\
\hline F5 & Elan & 0.737 & 0.748 & 0.986 & IRS & F37, F4, F11 & 0 \\
\hline
\end{tabular}

$\mathrm{TE}_{\mathrm{CRS}}$, relative efficiency under the assumption of constant return to scale; PTE $\mathrm{VRS}$, pure technical efficiency under the assumption of variable returns to scale; SE, scale efficiency; RTS, return to scale; IRS, increased returns to scale; DRS, decreased returns to scale.

relation to peer firms. In DEA, potential performance is not calculated based on theoretical criteria, but rather is based on comparison with other DMUs. Thus, the addition of removal of DMUs will most likely yield a different set of efficiency scores for the companies. Such additions or deletions could alter the set of companies lying on the efficient frontier. Additionally, as DEA calculation is based on surrogate input and output variables, if the study misses some important measures (that is, intangible assets), the researchers should verify its reliability and validity.

Issue 4. Identifying recent efficiency changes of benchmarking companies, the degree to which their efficiency has been improved, and which companies achieve efficiency improvement and thus can be used as a benchmark.

Figure 1 illustrates the Malmquist productivity index (efficiency change) of the following categories: relative efficiency in 1999, relative efficiency in 2002, shift in technology from 1999 to 2002 and catchup efficiency from 1999 to 2002. The figure shows that the efficiency changes of these 39 companies are positively correlated with shift in technology (0.888) and catching-up efficiency (CIE) (0.400) from 1999 to 2002 . However, the efficiency change is negatively correlated with 


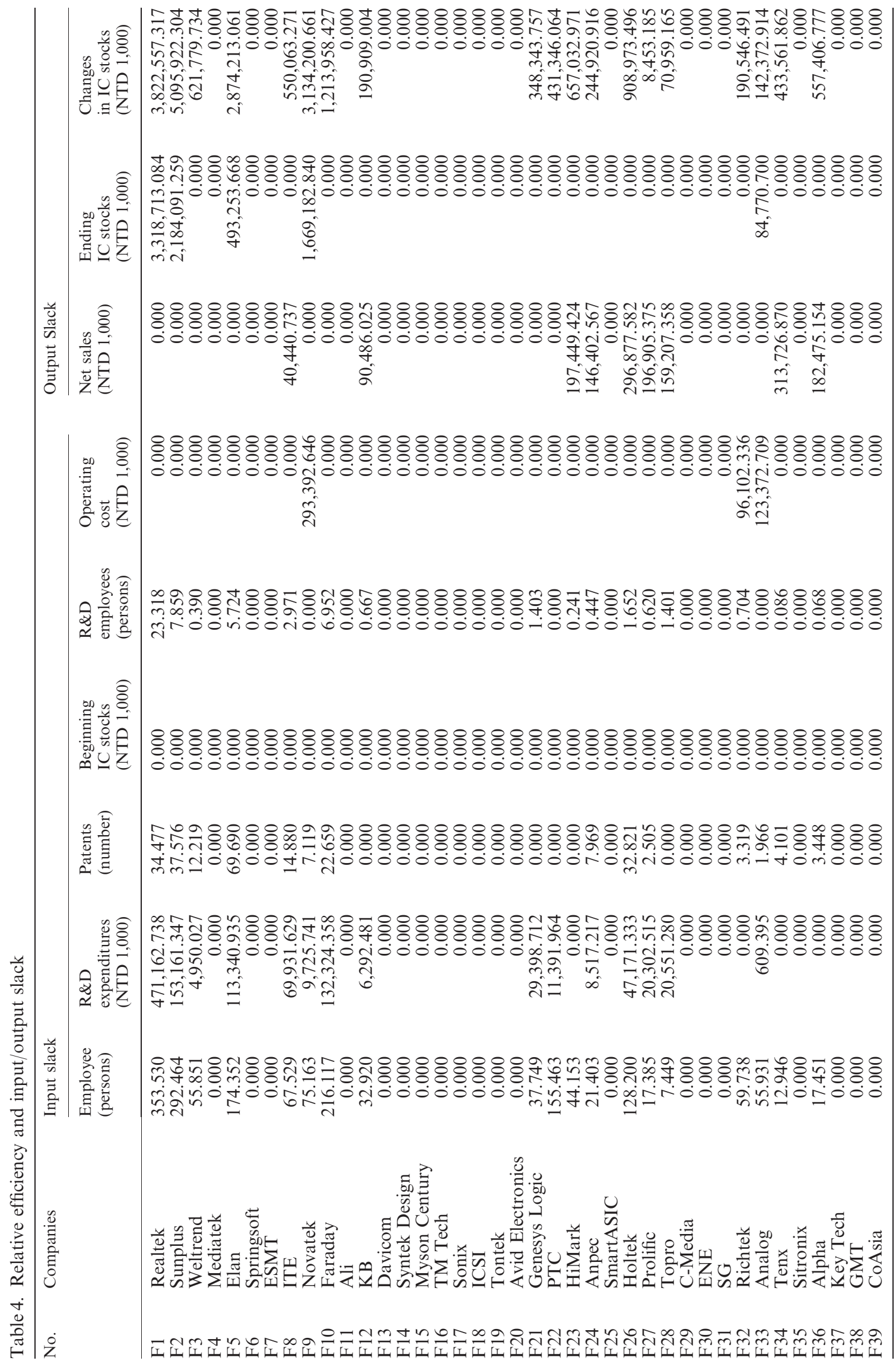


Wann-Yih Wu, Hsin-Ju Tsai, Kuei-Yang Cheng and Mengkuan Lai

Table 5. Comparison of efficient companies and inefficient companies

\begin{tabular}{lrrr}
\hline Ratio & $\begin{array}{r}\text { Efficient } \\
(N=20)\end{array}$ & \multicolumn{1}{l}{$\begin{array}{l}\text { Inefficient } \\
(N=19)\end{array}$} & Average \\
\hline Net sales/employees (NTD 1,000) & $21,381.14$ & $11,834.61$ & $16,607.88$ \\
Net sales/R\&D expenditures (NTD 1,000) & 12.11 & 8.85 & 10.48 \\
Net sales/patents (NTD 1,000) & $558,212.9$ & $122,917.29$ & $340,565.14$ \\
Changing intellectual capital stocks/employees (NTD 1,000) & $21,469.14$ & $10,691.48$ & $16,080.31$ \\
Changing intellectual capital stocks/R\&D expenditures (NTD 1,000) & 12.16 & 8.00 & 10.08 \\
Changing intellectual capital stocks/patents (NTD 1,000) & $560,510.39$ & $111,044.47$ & $335,777.43$ \\
\hline
\end{tabular}

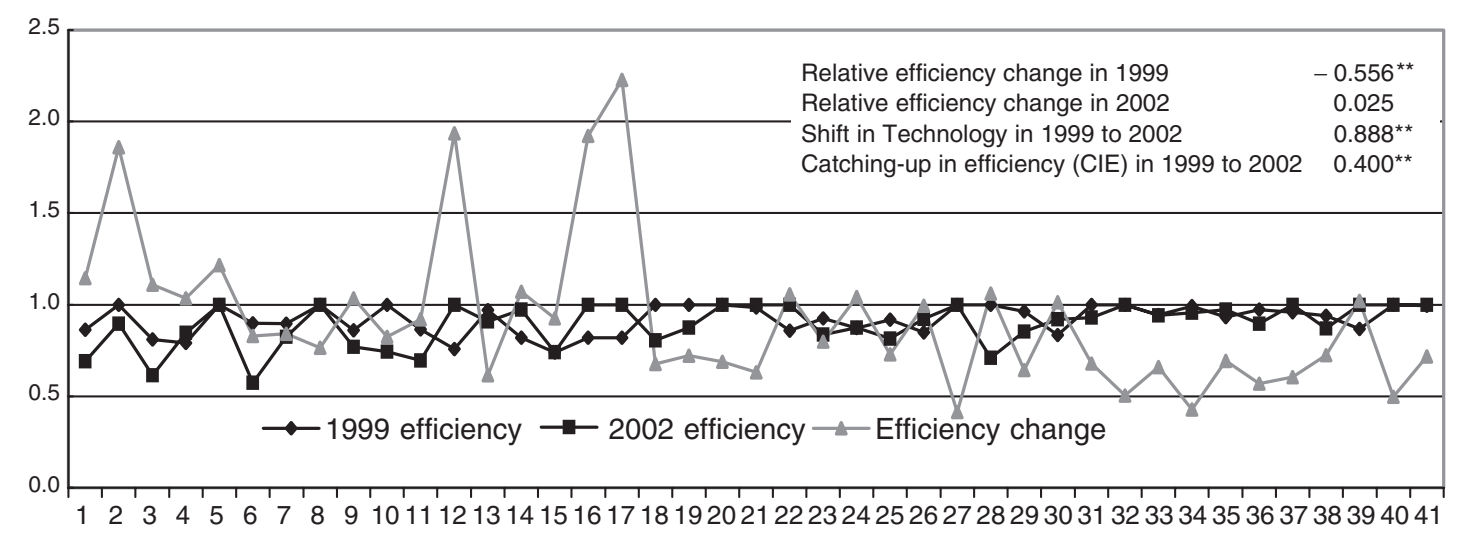

Figure 1. Diagram of relative efficiency and efficiency change of 39 Taiwan IC design companies.

relative efficiency in $1999(-0.556)$. This negative correlation indicates that between 1999 and 2002, firms who have achieved significant improvements in efficiency were those with poor relative efficiency in 1999. For example, Ali, Myson Century, Realtek and Sunplus exhibited a lagging relative efficiency in 1999, but achieved considerable improvements during the subsequent four years. In contrast, SmartASIC, ENE, GMT, CMedia and TM Tech, although had good relative efficiency in 1999, achieved little improvement during the subsequent four years. Thus, IC design firm executives need to compare industry-wide relative efficiency, shift in technology and catching-up in efficiency with company-wide efficiency. Such comparisons can provide a leading signal to help firms make necessary adjustments to R\&D and intellectual capital management strategies. Appendix A lists the detailed efficiency change and MPI values of 39 companies from 1999 to 2002.

Table 6 lists the six categories of 39 IC design companies, using levels of competitive advantages (MPI) and relative efficiency (TE) as the grouping variables. These categories are characterized as follows:

(1) High competitiveness and fast progress: From 1999-2002, these companies have improved rapidly. They were on the right track and should maintain their competitive advantages by continuing current strategies of intellectual capital management.

(2) High competitiveness but slow progress: These companies still enjoy good efficiency in managing intellectual capital, but have achieved no further progress in the four-year period. These companies thus need to achieve new breakthroughs.

(3) Medium competitiveness but fast progress: These companies have medium efficiency in managing intellectual capital but rapid efficiency change within the four-year period, indicating that they had gradual improvement.

(4) Medium competitiveness but slow progress: These companies have medium efficiency in managing intellectual capital. They had a slight decline in efficiency change from 1999 to 2002. These companies need to improve and catch up with their competitors.

(5) Low competitiveness but fast progress: The competitiveness of these companies lags behind others but they have superior efficiency significantly. These companies urgently need to continue their current efficiency improvement agenda to catch up with their competitors. 
Table 6. Six categories of IC design companies

\begin{tabular}{llll}
\hline Group & Competitiveness & Relative efficiency & IC design companies \\
\hline 1 & MPI $>1$ & $\mathrm{TE}_{2002}=1$ & Ali, Myson Century, Mediatek, Avid Electronics, Key Tech \\
2 & $\mathrm{MPI}<1$ & $\mathrm{TE}_{2002}=1$ & ESMT, CoAsia, ICSI, Tontek, Sitronix, ENE, GMT, SmartASIC \\
3 & $\mathrm{MPI}>1$ & $1>\mathrm{TE}_{2002}>0.8$ & $\begin{array}{l}\text { Davicom, Topro, PTC, Weltrend } \\
4\end{array}$ \\
$\mathrm{MPI}<1$ & $1>\mathrm{TE}_{2002}>0.8$ & $\begin{array}{c}\text { Analog, Richtek, SG, C-Media, Anpec, KB, Tenx, Sonix, Alpha, } \\
\end{array}$ \\
5 & $\mathrm{TPI}>1$ & $\mathrm{TE}_{2002}<0.8$ & Prolific Genesys Logic, Springsoft, HiMark, TM Tech \\
6 & $\mathrm{MPI}<1$ & $\mathrm{TE}_{2002}<0.8$ & Novatek, Syntek Design, Faraday, Elan \\
\hline
\end{tabular}

(6) Low competitiveness and slow progress: Not only does the competitiveness of these companies lag behind others but so too does their efficiency. This group most urgently requires a change of strategy in relation to intellectual capital management.

\section{Conclusions}

This research focuses on the relationship between intellectual capital and firm performance of Taiwan IC design companies using DEA and MPI as empirical instruments. Through a series of literature review, data collection and DEA analysis, this study reaches the following conclusions. Based on the efficiency analysis of Taiwan IC design companies in 2002, this study demonstrates that approximately one-third of the sampled companies have achieved relative satisfactory efficiency and been positioned on the efficiency frontier, while the remaining two-thirds have considerable room for improvement. The empirical results also help identify the benchmark partners that inefficient companies can learn from. Having clearly defined benchmarks helps companies improve their performance. Additionally, input and output slacks are measured to help inefficient companies identify a clear direction for progress. Company efficiency can achieve progress if the input values are reduced significantly by the gross input improvement, and/or the output values are augmented by the output improvement. It is extremely important for inefficient companies to identify which input and output factors need to be modified so that managers can pinpoint the major problems of the company accordingly.

The change of MPI from 1999 to 2002 also reveals that within a 4-year period, 15 companies improved their intellectual capital management efficiency. Restated, almost two thirds of the companies failed to improve their efficiency during the 4-year period. Individual firm competitiveness and pace of progress can be identified by comparing the relative efficiency and the rate of efficiency change of the IC design companies. Table 7 lists all of the results.

The above research results have several managerial implications. First, DEA has long been an efficient analytical tool for profit and non-profit organizations, but little has been mentioned about the applicability of DEA/MPI on knowledge-based industry, e.g. IC design companies, to evaluate management efficiency on intangible assets. The research results presented here thus provide useful information on this area for academics and practitioners. Second, the efficiency analysis of DEA as shown in this work, including input and output slack, benchmarking partners and MPI, provide meaningful implications efficiency management. This study suggests that through the adoption of benchmarking activities, firms can easily develop an implementation plan to catch up with benchmarking partners (Coombs et al., 1998).

Third, the data of benchmarking partners provide a meaningful reference to help firms increase their operating efficiency. The managers of inefficient IC design companies must use this analysis of strategy changes and efficiency improvement. The benchmarking partners can serve as the goal for management while simultaneously motivating employees. These benchmarking data thus provide one of the most efficient tools for communicating between managers and employees.

Fourth, the research results suggest that intellectual capital, which comprises human capital, customer capital, and structural capital is one of the main sources of competitive advantage for firms. This study argues that intellectual capital is a necessary strategic tool for use against competitors. The emphasis on intellectual capital can help firms implement new initiatives for enhancing their performance. 
Wann-Yih Wu, Hsin-Ju Tsai, Kuei-Yang Cheng and Mengkuan Lai

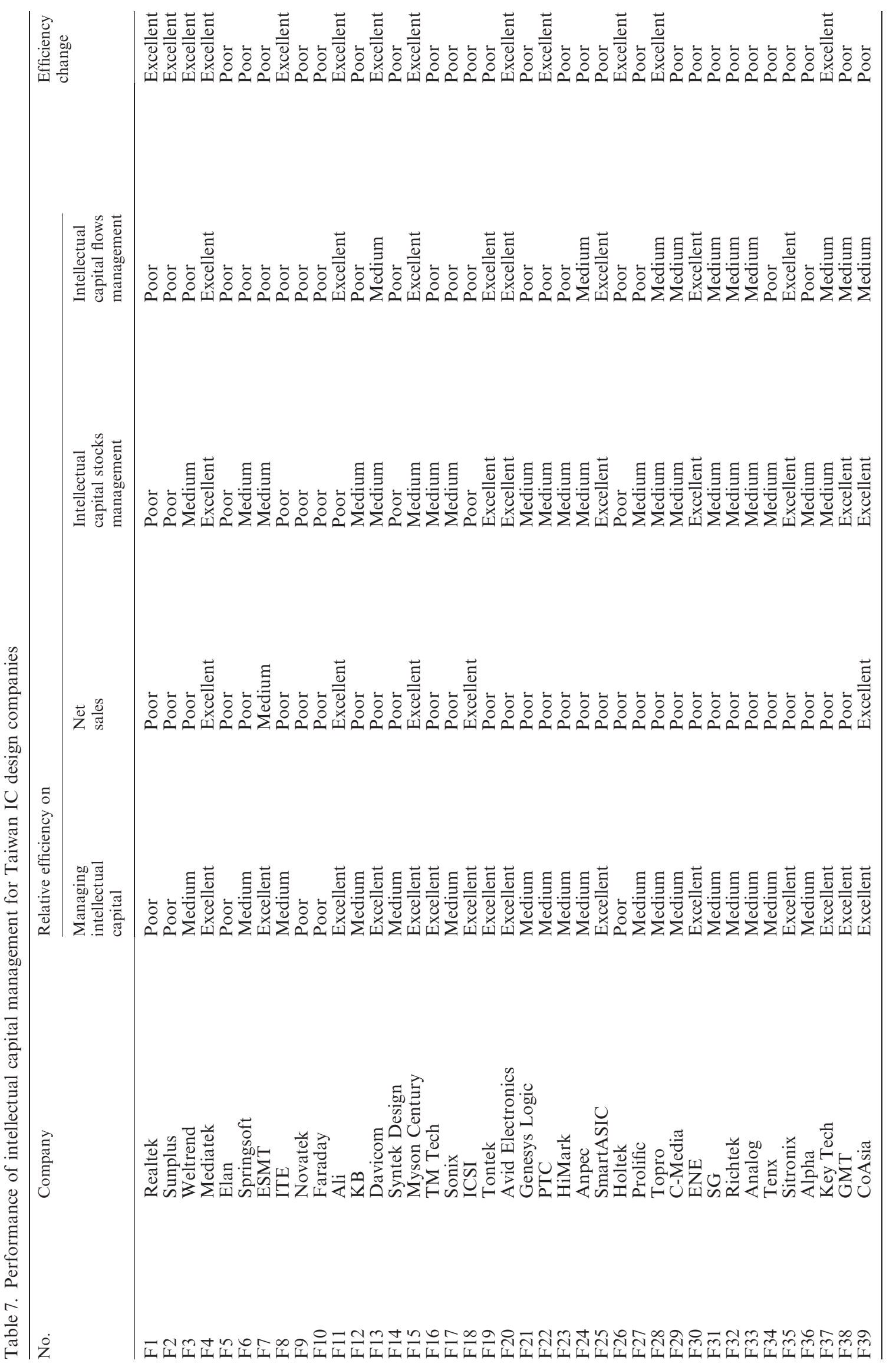


Fifth, measuring the efficiency of intellectual capital management and competitiveness of IC design firms will enable such firms to examine whether they have managed these vital intangible assets efficiently. Additionally, intellectual capital, particularly patents, intellectual property and R\&D teams, significantly influences the successes and failures of semiconductor companies.

Although the results of this study provide some practical insights of intellectual capital management particularly for knowledge-based companies, several suggestions can be made regarding future research directions. This study adopted DEA for the cross-sectional research design and examined Taiwanese IC design firms at one point in time. Meanwhile, MPI was also adopted to evaluate firm efficiency changes from 1999-2002. Consequently, this study examined little intertemporal relationships owing to the time constraints and data availability. Future researches are suggested to incorporate leading companies in IC design industry elsewhere, e.g. United States and Japan. Comparing IC design companies in different countries may have different findings on the significance of the input and/or output variables. On the other hand, observing the efficiency change in a longer period of time may be another option. Second, benchmarking management activities provide the most encouragement and incur the least resistance for the employees, compared with other management approaches e.g. management by objectives, and total quality management. Thus, the result of DEA as presented here should provide a clear implication to the managers of IC design companies. Employees tend to be more willing to follow the benchmarking strategy with fewer complaints, given that the benchmarks and operating records of the efficient companies are readily available and also accurate. In a benchmarking management process, the operating records of benchmarking partners speak for themselves when the managers use the records to motivate employees to achieve company goals.

\section{References}

Amit, R. and Schoemaker, P.J.H. (1993) Strategic assets and organizational rent. Strategic Management Journal, 14, 1, 33-46.

Banker, R.D., Charnes, A. and Cooper, W.W. (1984) Some models for estimating technological and scale inefficiencies in data envelopment analysis. Management Science, 30, 9, 1078-1092.
Barney, J. (1991) Firm resources and sustained competitive advantage. Journal of Management, 17, 1, 99-120.

Bontis, N. (1999) Managing organizational knowledge by diagnosing intellectual capital: framing and advancing the state of the field. International Journal of Technology Management, 18, 5/6/7/8, 433-462.

Bontis, N. (2001) Assessing knowledge assets: a review of the models used to measure intellectual capital. International Journal of Management Reviews, 3, 1, 41-60.

Breznitz, D. (2005) Development, flexibility and R\&D performance in the Taiwanese it industry: capability creation and the effects of state-industry coevolution. Industrial and Corporate Change, 14, 1, 153-187.

Brown, A., Osborn, T., Chan, J.M. and Jaganathan, V. (2005) Managing intellectual capital. Research-Technology Management, 48, 6, 34-41.

Caves, D.W., Christensen, L.R. and Diewert, W.E. (1982) The economic theory of index numbers and the measurement of input, output, and productivity. Econometrica, 50, 6, 1393-1414.

Chang, P.-L. (1993) Measuring the R\&D efficiency of manufacturing firms in Taiwan. Research project of the National Science Council (NSC), Institute of Management Science, National Chiao Tung University [in Chinese].

Chang, P.-L. and Tsai, C.-T. (2002) Finding the niche position - competition strategy of Taiwan's IC design industry. Technovation, 22, 2, 101-111.

Chang, S.-C., Lee, Z.-Y. and Yu, H.-C. (2003) Performance evaluation of IC design companies listed in TSE. Industry Forum, 5, 1. Available online at: http://www.itis.org.tw/forum/content5/02if37a.htm [in Chinese]

Charnes, A., Cooper, W.W. and Rhodes, E. (1978) Measuring the efficiency of decision making units. European Journal of Operational Research, 2, 6, 429-444.

Chatzkel, J. (2002) A conversation with Goran Roos. Journal of Intellectual Capital, 3, 2, 96-117.

Coombs, R., McMeekin, A. and Pybus, R. (1998) Toward the development of benchmarking tools for $\mathrm{R} \& \mathrm{D}$ project management. $R \& D$ Management, 28, 3 , 175-186.

Cooper, W.W., Park, K.S. and Yu, G. (2001) An illustrative application of idea (imprecise data envelopment analysis) to a Korean mobile telecommunication company. Operations Research, 49, 6, 807-820.

Despotis, D.K. (2005) Measuring human development via data envelopment analysis: the case of Asia and the pacific. Omega-International Journal of Management Science, 33, 5, 385-390.

Edvinsson, L. and Malone, M.S. (1997) Intellectual Capital: Realizing Your Company's True Value by Finding its Hidden Roots. New York: Harper Business.

Fare, R., Grosskopf, S., Lindgern, B. and Ross, P. (1992) Productivity changes in Swedish pharmacies 
Wann-Yih Wu, Hsin-Ju Tsai, Kuei-Yang Cheng and Mengkuan Lai

1980-1989: a non-parametric Malmquist approach. Journal of Productivity Analysis, 3, 85-101.

Golany, B. and Roll, Y. (1989) An application procedure for DEA. Omega, 17, 3, 237-250.

Hattori, T., Jamasb, T. and Pollitt, M. (2005) Electricity distribution in the UK and Japan: a comparative efficiency analysis 1985-1998. Energy Journal, 26, 2, 23-47.

Johnson, W.H.A. (1999) An integrative taxonomy of intellectual capital: measuring the stock and flow of intellectual capital components in the firm. International Journal of Technology Management, 18, 5/6/7/ 8, 562-575.

Kao, C., Hwang, S.N. and Sueyoshi, T. (2003) Management Performance Evaluation: Data Envelopment Analysis (in Chinese). Taipei: Hwatai.

Kauffmann, P. and Unal, R. (2000) A model for allocating resources to research programs by evaluating technical importance and research productivity. Engineering Management Journal, 12, 1, 5-9.

Kfir, R. (2000) A framework, process and tool for managing technology-based assets. $R \& D$ Management, 30, 4, 297-304.

Kozmetsky, G. and Yue, P. (1998) Comparative performance of global semiconductor companies. Omega, 26, 2, 153-175.

Linton, J.D. and Cook, W.D. (1998) Technology implementation: a comparative study of Canadian and U.S. Factories. INFOR (Information Systems and Operational Research), 36, 3, 142-150.

Linton, J.D., Walsh, S.T. and Morabito, J. (2002) Analysis, ranking and selection of R\&D projects in a portfolio. R\&D Management, 32, 2, 139-148.

Oral, M., Kettani, O. and Lang, P. (1991) A methodology for collective evaluation and selection of industrial R\&D projects. Management Science, 37, 7, 871-885.

Pulic, A. (2000) Vaictm - an accounting tool for IC management. International Journal of Technology Management, 20, 5678, 702-714.

Reitsperger, W.D., Daniel, S.J., Tallman, S.B. and Chismar, W.G. (1993) Product quality and cost leadership: compatible strategies? Management International Review, 33, 1, 7-21.
Roos, G. and Roos, J. (1997) Measuring your company's intellectual performance. Long Range Planning, 30, 3, 413-426.

Shao, B.B.M. and Lin, W.T. (2002) Technical efficiency analysis of information technology investments: a two-stage empirical investigation. Information and Management, 39, 5, 391-401.

Snow, D.C. (1983) Evolution of a patent classification system. World Patent Information, 5, 4, 213-218.

Stewart, T.A. (1997) Intellectual Capital: The New Wealth of Organizations. New York: Douleday/ Currency.

SubbaNarasimha, P.N., Ahmad, S. and Mallya, S.N. (2003) Technological knowledge and firm performance of pharmaceutical firms. Journal of Intellectual Capital, 4, 1, 20-33.

Sueyoshi, T. and Goto, M. (2001) Slack-adjusted DEA for time series analysis: performance measurement of Japanese electric power generation industry in 1984-1993. European Journal of Operational Research, 133, 2, 232-259.

Sullivan, P.H. (2000) Value-Driven Intellectual Capital: How to Convert Intangible Corporate Assets Into Market Value. New York: Wiley.

Sveiby, K.E. (1997) The New Organizational Wealth: Managing \& Measuring Knowledge-Based Assets (1st ed). San Francisco: Berrett-Koehler Publishers.

Thore, S., Phillips, F., Ruefli, T.W. and Yue, P. (1996) DEA and the management of the product cycle: the U.S. Computer industry. Computers and Operations Research, 23, 4, 341-356.

Van Buren, M.E. (1999) A yardstick for knowledge management. Training and Development, 53, 5, 71-78.

Verma, D. and Sinha, K.K. (2002) Toward a theory of project interdependencies in high tech R\&D environments. Journal of Operations Management, 20, 5, 451-468.

Wang, J.C. and Tsai, K.H. (2005) Development strategies and prospects for Taiwan's R\&D service industry. International Journal of Technology Management, 29, 3-4, 308-326.

Wernerfelt, B. (1984) A resource-based view of the firm. Strategic Management Journal, 5, 2, $171-180$.

\section{Appendix A}

Table A. Efficiency change of 39 Taiwan IC design companies from 1999 to 2002

\begin{tabular}{llllllll}
\hline Group & No. & Company & TE $_{1999}$ & TE $_{2002}$ & CIE $_{1999 \rightarrow 2002}$ & SIE & MPI \\
\hline Group 1: High competitiveness & F11 & Ali & 0.758 & 1.000 & 1.320 & 1.466 & 1.935 \\
and fast pace of progress & F15 & Myson Century & 0.820 & 1.000 & 1.220 & 1.576 & 1.922 \\
& F4 & Mediatek & 1.000 & 1.000 & 1.000 & 1.217 & 1.217 \\
& F20 & Avid Electronics & 0.857 & 1.000 & 1.167 & 0.906 & 1.057 \\
& F37 & Key Tech & 0.867 & 1.000 & 1.153 & 0.885 & 1.021
\end{tabular}


Table A. (Contd.)

\begin{tabular}{|c|c|c|c|c|c|c|c|}
\hline Group & No. & Company & $\mathrm{TE}_{1999}$ & $\mathrm{TE}_{2002}$ & $\mathrm{CIE}_{1999} \rightarrow 2002$ & SIE & MPI \\
\hline \multirow{12}{*}{$\begin{array}{l}\text { Group 2: High competitiveness } \\
\text { but slow pace of progress }\end{array}$} & F7 & ESMT & 1.000 & 1.000 & 1.000 & 0.766 & 0.766 \\
\hline & F18 & ICSI & 1.000 & 1.000 & 1.000 & 0.689 & 0.689 \\
\hline & F19 & Tontek & 0.984 & 1.000 & 1.016 & 0.620 & 0.630 \\
\hline & F35 & Sitronix & 0.958 & 1.000 & 1.044 & 0.578 & 0.604 \\
\hline & F30 & ENE & 1.000 & 1.000 & 1.000 & 0.505 & 0.505 \\
\hline & F38 & GMT & 1.000 & 1.000 & 1.000 & 0.496 & 0.496 \\
\hline & F25 & SmartASIC & 1.000 & 1.000 & 1.000 & 0.413 & 0.413 \\
\hline & F39 & CoAsia & 0.994 & 1.000 & 1.006 & 0.711 & 0.716 \\
\hline & F15 & Davicom & 0.819 & 0.974 & 1.189 & 0.901 & 1.071 \\
\hline & F22 & PTC & 0.873 & 0.875 & 1.003 & 1.039 & 1.042 \\
\hline & F3 & Weltrend & 0.790 & 0.845 & 1.070 & 0.967 & 1.034 \\
\hline & F28 & Topro & 0.833 & 0.919 & 1.103 & 0.919 & 1.013 \\
\hline \multirow{14}{*}{$\begin{array}{l}\text { Group 4: Medium competitiveness } \\
\text { but slow pace of progress }\end{array}$} & F24 & Anpec & 0.848 & 0.923 & 1.088 & 0.914 & 0.994 \\
\hline & F6 & Springsoft & 0.896 & 0.825 & 0.920 & 0.914 & 0.841 \\
\hline & F21 & Genesys Logic & 0.926 & 0.836 & 0.903 & 0.885 & 0.799 \\
\hline & F23 & HiMark & 0.917 & 0.814 & 0.887 & 0.822 & 0.729 \\
\hline & F36 & Alpha & 0.939 & 0.869 & 0.925 & 0.783 & 0.725 \\
\hline & F17 & Sonix & 1.000 & 0.875 & 0.875 & 0.825 & 0.722 \\
\hline & F33 & Analog & 0.933 & 0.973 & 1.043 & 0.664 & 0.692 \\
\hline & F29 & C-Media & 1.000 & 0.930 & 0.930 & 0.730 & 0.678 \\
\hline & F16 & TM Tech & 1.000 & 0.805 & 0.805 & 0.840 & 0.677 \\
\hline & F31 & SG & 0.944 & 0.943 & 0.999 & 0.661 & 0.660 \\
\hline & F27 & Prolific & 0.962 & 0.854 & 0.887 & 0.725 & 0.643 \\
\hline & F12 & KB & 0.970 & 0.909 & 0.937 & 0.655 & 0.614 \\
\hline & F34 & Tenx & 0.974 & 0.897 & 0.921 & 0.619 & 0.570 \\
\hline & F32 & Richtek & 0.991 & 0.957 & 0.965 & 0.443 & 0.428 \\
\hline \multirow{4}{*}{$\begin{array}{l}\text { Group 5: Low competitiveness } \\
\text { but fast pace of progress }\end{array}$} & F1 & Realtek & 0.862 & 0.690 & 0.800 & 1.430 & 1.145 \\
\hline & $\mathrm{F} 2$ & Sunplus & 0.811 & 0.615 & 0.758 & 1.465 & 1.110 \\
\hline & F26 & Holtek & 1.000 & 0.710 & 0.710 & 1.493 & 1.061 \\
\hline & F8 & ITE & 0.861 & 0.770 & 0.894 & 1.158 & 1.035 \\
\hline \multirow{5}{*}{$\begin{array}{l}\text { Group 6: Low competitiveness and } \\
\text { low pace of progress }\end{array}$} & F14 & Syntek Design & 0.739 & 0.740 & 1.002 & 0.924 & 0.926 \\
\hline & F10 & Faraday & 0.865 & 0.695 & 0.804 & 1.146 & 0.920 \\
\hline & F5 & Elan & 0.900 & 0.573 & 0.637 & 1.304 & 0.830 \\
\hline & F9 & Novatek & 1.000 & 0.743 & 0.743 & 1.109 & 0.824 \\
\hline & Mean & & 0.920 & 0.889 & 0.972 & 0.953 & 0.923 \\
\hline
\end{tabular}

